\title{
Molecular Characterisation of Carbapenem-Resistant Enterobacteriaceae from Intensive Care Units
}

\author{
Azka Fatima, Rubina Kamran, Haniya Rashid and Muhammad Shafique \\ Department of Microbiology and Pathology, Pakistan Institute of Medical Sciences (PIMS), SZABMU, Islamabad, Pakistan
}

\begin{abstract}
Objective: To determine the molecular characterisation of carbapenem-resistant enterobacteriaceae (CRE) from patients admitted in intensive care units (ICUs) of a tertiary care hospital.

Study Design: Descriptive study.

Place and Duration of Study: Department of Pathology and Microbiology, Pakistan Institute of Medical Sciences (PIMS), SZABMU, Islamabad, Pakistan, from July 2015 to March 2016.

Methodology: Fifty isolates of CRE from intensive care units samples were processed, collected through samples coming from ICUs. Specimens were cultured on blood and Mac Conkey agar, and organisms were identified. Resistant organisms to imipenem and meropenem were preserved in glycerol broth at $-80^{\circ} \mathrm{C}$. Their molecular characterisation was done using the conventional PCR targeting NDM, KPC, VIM and IMP genes.

Results: Out of 50 samples, $13(26 \%)$ were from urine, $13(26 \%)$ from endotracheal tube tip, 7 (14\%) from blood, 7 (14\%) from pus, 7 (14\%) from tracheal secretions, $2(4 \%)$ from fluids, and $1(2 \%)$ from catheter tip. NDM genes was isolated in $56 \%$ isolates. VIM, KPC, and IMP genes were not found in any isolates. NDM positive isolates included $86 \%$ Klebsiella pneumonia, $10 \%$ Escherichia coli, and $4 \%$ Klebsiella oxytoca.

Conclusion: NDM gene was present in $28(56 \%)$ samples. Whereas, VIM gene, KPC gene, and IMP genes were not detected in the CRE samples.
\end{abstract}

Key Words: Enterobacteriaceae, Carbapenem resistance, PCR, Molecular characterisation, NDM gene.

How to cite this article: Fatima $\mathrm{A}$, Kamran $\mathrm{R}$, Rashid $\mathrm{H}$, Shafique M. Molecular characterisation of carbapenem-resistant enterobacteriaceae from intensive care units. J Coll Physicians Surg Pak 2019; 29(9): 878-81.

\section{INTRODUCTION}

Enterobacteriacea infections are major cause of morbidity and mortality in world nowadays. These organisms are surviving in the hospital environment because of their acquired resistance to several commonly used antibiotics and, perhaps more important, their ability to acquire resistance to all currently available antibiotics, either by mutation or by receipt of foreign genetic material through the transfer of plasmids and transposons. Prevalence of carbapenem resistant Enterobacteriacea is emerging worldwide, i.e. Acinetobacter 88\%, Klebsiella 67\%, E. coli 49\%; other organisms are also showing similar resistance patterns. 1

Enterobacteriaceae are prevalent causes of both healthcare and community infections, raising the possibility of metastasise CRE into the community. There are limited therapeutic options available to treat patients infected with these pan resistant organisms. CRE has gained epidemiologic importance nationally and internationally. ${ }^{2}$

Correspondence to: Dr. Azka Fatima, Department of Microbiology and Pathology, Pakistan Institute of Medical Sciences (PIMS), SZABMU, Islamabad, Pakistan

E-mail:azkafatimadub@yahoo.com

Received: November 27, 2017; Revised: January 21, 2019; Accepted: March 07, 2019
The referral of the patients is the potential source of transmitting the infection to a hospital. Though infection control practices are optimally observed, but the huge patient burden undermines the desired standards. In these conditions, the treating physicians are handicapped due to limited options to treat these multidrug resistant organisms. Molecular characterisation helps in formulating a better empiric therapy and discourage use of ineffective and needless antibiotics. Further, this study will provide a benchmark for more advanced studies to discover the resistance mechanisms other than the studied.

The aim of this study was to determine the molecular characterisation of carbapenem resistant Enterobacteriaceae (CRE) from patients admitted in intensive care units (ICUs) of a tertiary care hospital.

\section{METHODOLOGY}

This descriptive, cross-sectional study was conducted from July 2015 to March 2016 in Department of Pathology and Microbiology, Pakistan Institute of Medical Sciences (PIMS), Islamabad. A proforma was used as a tool for data collection. Fifty isolates of carbapenem resistant Enterobacteriaceae (CRE) from intensive care units samples were analysed with standard laboratory techniques. 
Table I: Technical details about genes, primers \& PCR conditions.

\begin{tabular}{|c|c|c|c|c|}
\hline Primer & Sequence $\left(5^{\prime}-3^{\prime}\right)$ & $\begin{array}{l}\text { PCR product } \\
\text { size (bp) }\end{array}$ & PCR conditions & References \\
\hline $\begin{array}{l}\text { IMP-A } \\
\text { IMP-B }\end{array}$ & $\begin{array}{l}\text { GAAGGYGTTTATGTTCATAC }(\mathrm{Y}=\mathrm{C} \text { or } \mathrm{T}) \\
\text { GTAMGTTTCAAGAGTGATGC }(\mathrm{M}=\mathrm{A} \text { or } \mathrm{C})\end{array}$ & 587 & $\begin{array}{l}10 \mathrm{~min} \text { at } 94^{\circ} \mathrm{C} ; 36 \mathrm{cycles} \text { of amplification consisting of } 30 \mathrm{~s} \\
\text { at } 94^{\circ} \mathrm{C}, 40 \mathrm{~s} \text { at } 52^{\circ} \mathrm{C} \text {, and } 50 \mathrm{~s} \text { at } 72^{\circ} \mathrm{C} \text {; and } 5 \mathrm{~min} \text { at } 72^{\circ} \mathrm{C} \\
\text { for the final extension. }\end{array}$ & 6 \\
\hline $\begin{array}{l}\text { VIM2004A } \\
\text { VIM2004A }\end{array}$ & $\begin{array}{l}\text { GTTTGGTCGCATATCGCAAC } \\
\text { AATGCGCAGCACCAGGATAG }\end{array}$ & 382 & $\begin{array}{l}\text { Initial denaturation step at } 94^{\circ} \mathrm{C} \text { for } 5 \mathrm{~min} \text {, and } 30 \text { cycles consisting } \\
\text { of denaturation at } 94^{\circ} \mathrm{C} \text { for } 1 \mathrm{~min} \text {, annealing at } 54^{\circ} \mathrm{C} \text { for } 1 \mathrm{~min} \\
\text { and primer extension at } 72^{\circ} \mathrm{C} \text { for } 1.5 \mathrm{~min} \text {. }\end{array}$ & 7 \\
\hline $\begin{array}{l}\text { NDM-F } \\
\text { NDM-R }\end{array}$ & $\begin{array}{l}\text { GGTTTGGCGATCTGGTTTTC } \\
\text { CGGAATGGCTCATCACGATC }\end{array}$ & 621 & $\begin{array}{l}94^{\circ} \mathrm{C}(5 \mathrm{~min}) \\
{\left[94^{\circ} \mathrm{C}(30 \mathrm{~s}) 55^{\circ} \mathrm{C}(30 \mathrm{~s})\right] \times 30 \text { cycles }} \\
72^{\circ} \mathrm{C}(50 \mathrm{~s}) \\
72^{\circ} \mathrm{C}(5 \mathrm{~min})\end{array}$ & 8 \\
\hline $\begin{array}{l}\text { KPC-F } \\
\text { KPC-R }\end{array}$ & $\begin{array}{l}\text { CGTCTAGTTCTGCTGTCTTG } \\
\text { CTTGTCATCCTTGTTAGGCG }\end{array}$ & 798 & $\begin{array}{l}94^{\circ} \mathrm{C} 3 \mathrm{~min}+30 \text { cylces of }\left(95^{\circ} \mathrm{C} 1 \mathrm{~min}+55^{\circ} \mathrm{C} 31 \mathrm{~s}+73^{\circ} \mathrm{C} 1 \mathrm{~min}\right) \\
+72^{\circ} \mathrm{C} 5 \mathrm{~min} .\end{array}$ & 9 \\
\hline
\end{tabular}

The samples included urine, pus, blood, catheter tip, tracheal secretions, endotracheal tube and fluid. Culturing of bacterial isolates was done on blood agar and Mac Conkey's agar media. Urine samples were cultured on cystine lactose electrolyte deficient (CLED) agar. Primary identification was carried out by gram staining, growth characteristics, on Mac Conkey agar followed by standard biochemical methods i.e. API 20E (Biomeriuex, France).

Antibiotic susceptibility testing was carried out using Kirby-Bauer disk diffusion method. ${ }^{3}$ The results were interpreted according to Clinical Laboratory Standard Institute 2014 Guidelines. ${ }^{4}$

Escherichia coli ATCC 25922 was used as control in susceptibility testing; negative control regarding ESBL phenomenon and absence of genes whereas K. pneumoniae ATCC 700603 was used as positive control regarding ESBL phenomenon. Positive controls regarding IMP, VIM, KPC, and NDM gene were acquired from Quaid-i-Azam University. ${ }^{5}$ Conventional PCR was done to find out NDM, KPC, IPM, VIM gene. Table I describes the method of PCR. ${ }^{6-9}$

\section{RESULTS}

Carbapenem-resistant Enterobacteriaceae isolated from samples from 10 Intensive care units of the hospital, were included. Minimum age of patient was second day of life while maximum was 80 years.

Majority of samples were received from medical intensive care unit $24(48 \%)$, followed by surgical intensive care unit $14(28 \%)$, pediatric intensive care unit $4(8 \%)$, and neonatal intensive care unit $8(16 \%)$. Out of 50 samples, $13(26 \%)$ were from urine, $13(26 \%)$ from endotracheal tube tip, 7 (14\%) from blood, 7 (14\%) from pus, $7(14 \%)$ from tracheal secretions, $2(4 \%)$ from fluids and $1(2 \%)$ were from catheter tip.

KPC gene was not detected in all 50 samples using forward and reverse primers mix, with standard PCR conditions and reagents. Expected band size of KPC
PCR product was $798 \mathrm{bp}$. VIM gene was not detected in all 50 samples using forward and reverse primers mix, with standard PCR conditions and reagents. Expected band size of VIM PCR product was $382 \mathrm{bp}$. IMP gene was not detected in all 50 samples using forward and reverse primers mix, with standard PCR conditions and reagents. Expected band size of IMP PCR product was $587 \mathrm{bp}$. Expected PCR product size for NDM gene was $621 \mathrm{bp}$. NDM gene was amplified in 28 samples out of 50 $(56 \%)$.

NDM gene was isolated in $24(86 \%)$ isolates of Klebsiella pneumoniae, followed by E. coli $3(10 \%)$, and Klebsiella oxytoca 1 (4\%).

\section{DISCUSSION}

During the past decade, the increase in antibiotic resistance in Enterobacteriaceae has become a major concern worldwide. Beta-lactams have been widely used as the mainstay of treatment for severe infections due to these bacteria, with carbapenems often representing last-resource drugs. Carbapenem resistance due to acquired carbapenemases has emerged and spread worldwide since the early 2000 s and spread rapidly among the bacteria and also became common source of hospital-acquired infections. Carbapenemases have been studied in depth, and is characterised on the basis of enzymes production, now classified as class B (metallo-beta-lactamases, MBLs), class $A$ and class $D$ (serine carbapenemases). ${ }^{10}$ The most widespread carbapenemases so far in Enterobacteriaceae is the KPC-type class-A carbapenemase, which has been found in Klebsiella pneumoniae, in the United States, Asia, the United Kingdom, Israel, and southern Europe. ${ }^{11}$ In the Indian subcontinent, NDM is the most prevalent carbapenemase. Interestingly, acquired carbapenemases have mainly been restricted to geographical areas and to specific bacterial species, and outbreaks as well as spread in other countries has often been associated with imported cases from those countries where the bacteria are endemic. Population 
mobility is known to be a main factor in globalisation and spread of antimicrobial drug-resistance among organisms.12 For example, the emergence of KPCproducing Enterobacteriaceae in the United States in 2001,11 could be later associated with the emergence of travel-related outbreaks in other countries. 10,11,13,14

In this study of 50 samples, 13 (26\%) were isolated from urine and endotracheal tube tip each, 7 (14\%) from blood, 7 (14\%) from pus, and tracheal secretions each, 2 (4\%) from fluids, and 1 (2\%) from catheter tip. Barran et al. from Turkey in 2016 isolated majority of CRE strains from internal medicine intensive care unit (ICU) $(27.07 \%)$. This was followed by post-anesthesia care unit (PACU) (9.94\%), surgical ICU (5.52\%). ${ }^{15}$

The unique nature of the intensive care unit (ICU) environment makes this part of the hospital a focus for the emergence and spread of many MDR pathogens. There are plenty of opportunities for the crosstransmission of resistant bacteria from patient to patient, as patients are commonly exposed to broad-spectrum antimicrobial agents and any breach in infection control practices will spread the MDR bacteria more rapidly. Increased resistance to multiple drugs is associated with hospital-acquired infections among ICU patients, and the resistance rates are almost universally higher among ICU patients than non-ICU patients. Longer time hospitalisation ( $>7$ days) increases the risk of about twoto three-times to be infected with a pathogen possessing an antimicrobial-resistance.

In this study, bla NDM gene is present in 28 (56\%) samples. Whereas, bla VIM gene, bla KPC gene, bla IMP gene are not detected at all in the CRE samples. NDM gene positive isolates, $24(86 \%)$ were Klebsiella pneumoniae, 3 (10\%) were Escherichia coli and 1 (4\%) was Klebsiella oxytoca.

Naheed et al. conducted a study in Pakistan in 2013. They collected clinical samples from two hospitals of Lahore and Islamabad, Pakistan. On PCR amplification $23.6 \%$ isolates were harbouring bla NDM-1 gene, $25.1 \%$ isolates having bla VIM gene, and $1.5 \%$ isolates display bla IMP gene. ${ }^{16}$ Bla NDM-1 is located on remarkably plastic plasmids - genetic structures that can move with ease from one bacterium to another - and it is now very clear that bla NDM-1 plasmids are highly promiscuous. It can easily spread among various species and transmit the resistance genes.

Resistance to commonly prescribed antibiotics is increasing day-by-day in our country. Surveillance for antimicrobial resistance among bacterial pathogens in hospitals, particularly in ICU settings with a preexisting higher resistance burden, is mandatory in establishing and/or modifying guidelines for empirical treatment of severe infections in ICU patients caused by these antimicrobial-resistant pathogens.
In 2014, Rahman et al. conducted a study in India and noted that all carbapenem-resistant isolates in their study were bla NDM-positive by PCR. ${ }^{14}$

In 2012, Hu et al. reported $75.3 \%$ bla KPC gene detected in their isolates, bla VIM gene in $2.6 \%$ isolates, and bla IMP gene in $4 \%$ isolates. They screened 77 isolates of Enterobacteriaceae for the bla NDM-1 gene; however, none was found to be NDM-1-producing. ${ }^{17}$

The massive use of antibacterial drugs in the medical and veterinary practice, food industries, agriculture and commercial ethanol production and increased production of these drugs globally has also contributed to the environmental antibiotic pollution leading to destruction of useful bacteria and favouring the selection of resistant bacteria.

However, there are many opportunities to prevent the emergence and spread of these resistant pathogens through improved use of established infection control measures like patient isolation, hand washing, glove use, and appropriate gown use and judicious use of antibiotics.

there were certain limitations of the study. Clinical antibiotic history and outcome of the patients were not correlated. The sample size was also very small.

\section{CONCLUSION}

In this study, NDM gene was present in $56 \%$ samples. VIM gene, KPC gene, and IMP gene were not detected in none of the CRE samples. NDM positive isolates included $86 \%$ Klebsiella pneumoniae, 10\% Escherichia coli, and $4 \%$ Klebsiella oxytoca. In $44 \%$ isolates, no gene was detected, which implies that other genes encoding carbapenemases enzymes may be present in this part of the world.

\section{CONFLICT OF INTEREST:}

Authors declared no conflict of interest.

\section{AUTHORS' CONTRIBUTION:}

HR: Sample collection and initial processing.

AF: PCR and final analysis and writing the manuscript. MS: Statistics and result analysis.

RK: Final proof reading and carrying out corrections.

\section{REFERENCES}

1. UK standards for microbiology investigations. Detection and reporting of bacteria with carbapenem-hydrolyzing beta lactamases. UK Protocols 2014; 1.1:1-25.

2. Gupta N, Limbago BM, Patel JB, Kallen AJ. Carbapenemresistant enterobacteriaceae: Epidemiology and prevention. Clin Infect Dis 2011; 53:60-7.

3. Hudzicki J. Kirby-bauer disk diffusion susceptibility test protocol. American Society for Microbiology 2009.

4. Clinical and laboratory standards institute (CLSI) performance standards for antimicrobial susceptibility testing; Twenty-fourth 
informational supplement. CLSI document M100-S24. Clinical and Laboratory Standards Institute 2014: 34.

5. Sattar H, Toleman M, Nahid F, Zahra R. Co-existence of blaNDM-1 and blaKPC-2 in clinical isolates of klebsiella pneumoniae from Pakistan. J Chemother 2016; 28:346-9.

6. http://jcm.asm.org/content/50/12/3877/T1.expansion

7. https://www.spandidos-publications.com/mmr/11/1/494

8. https://open.uct.ac.za/bitstream/item/16672/thesis_hsf_2015 manenzhe rendani innocent.pdf?sequence $=1$

9. http://wwwnc.cdc.gov/eid/article/17/10/11-0655-t3

10. Navon-Venezia S, Leavitt A, Schwaber MJ, Rasheed JK, Srinivasan A, Patel JB, et al. First report on a hyperepidemic clone of KPC-3-producing klebsiella pneumoniae in Israel genetically related to a strain causing outbreaks in the United States. Antimicrob Agents Chemother 2009; 53:818-20.

11. Nordmann P, Cuzon G, Naas T. The real threat of klebsiella pneumoniae carbapenemase-producing bacteria. Lancet Infect Dis 2009; 9:228-36.

12. Khan E, Ejaz M, Zafar A, Jabeen K, Shakoor S, Inayat R, et al. Increased isolation of ESBL producing klebsiella pneumoniae with emergence of carbapenem resistant isolates in Pakistan: Report from a tertiary care hospital. J Pak Med Assoc 2010; 60:186-90.

13. Rosenthal J. Climate change and the geographic distribution of infectious diseases. EcoHealth 2009; 6:489-95.

14. Rahman M, Shukla SK, Prasad KN, Ovejero CM, Pati BK, Tripathi $\mathrm{A}$, et al. Prevalence and molecular characterisation of New Delhi metallo- $\beta$-lactamases NDM-1, NDM-5, NDM-6 and NDM-7 in multidrug-resistant enterobacteriaceae from India. Int J Antimicrob Agents 2014; 44:30-7.

15. Baran I, Aksu N. Phenotypic and genotypic characteristics of carbapenem-resistant enterobacteriaceae in a tertiary-level reference hospital in Turkey. Ann Clin Microbiol Antimicrob 2016; 15:20.

16. Nahid F, Khan AA, Rehman S, Zahra R. Prevalence of metallo$\beta$-lactamase NDM-1-producing multi-drug resistant bacteria at two Pakistani hospitals and implications for public health. J Infect Public Health 2013; 6:487-93.

17. Hu F, Chen S, Xu X, Guo Y, Liu Y, Zhu D, et al. Emergence of carbapenem-resistant clinical enterobacteriaceae isolates from a teaching hospital in Shanghai, China. J Med Microbiol 2012; 61:132-6. 